\title{
Evaluation of Phenolic Compounds and Antioxidant and Antimicrobial Activities of Some Common Herbs
}

\author{
Muhammad Abdul Qadir,, Syeda Kiran Shahzadi, ${ }^{1}$ Asad Bashir, ${ }^{2}$ \\ Adil Munir, ${ }^{2}$ and Shabnam Shahzad ${ }^{1}$ \\ ${ }^{1}$ Institute of Chemistry, University of the Punjab, Lahore 54590, Pakistan \\ ${ }^{2}$ Department of Chemistry, Minhaj University, Lahore 54590, Pakistan \\ Correspondence should be addressed to Syeda Kiran Shahzadi; kiran.syyed@gmail.com
}

Received 10 August 2016; Accepted 1 November 2016; Published 16 February 2017

Academic Editor: Mohamed Abdel-Rehim

Copyright (C) 2017 Muhammad Abdul Qadir et al. This is an open access article distributed under the Creative Commons Attribution License, which permits unrestricted use, distribution, and reproduction in any medium, provided the original work is properly cited.

\begin{abstract}
The study was designed to evaluate the phenolic, flavonoid contents and antioxidant and antimicrobial activities of onion (Allium cepa), garlic (Allium sativum), mint (Mentha spicata), thyme (Thymus vulgaris), oak (Quercus), aloe vera (Aloe barbadensis Miller), and ginger (Zingiber officinale). All extracts showed a wide range of total phenolic contents, that is, 4.96 to $98.37 \mathrm{mg} / 100 \mathrm{~g}$ gallic acid equivalents, and total flavonoid contents, that is, 0.41 to $17.64 \mathrm{mg} / 100 \mathrm{~g}$ catechin equivalents. Antioxidant activity (AA) was determined by measuring reducing power, inhibition of peroxidation using linoleic acid system, and 2,2-diphenyl-1-picrylhydrazyl radical (DPPH) scavenging activity. Different extracts inhibited oxidation of linoleic acid by $16.6-84.2 \%$ while DPPH radical scavenging activity ( $\mathrm{IC}_{50}$ values) ranged from $17.8 \%$ to $79.1 \mu \mathrm{g} / \mathrm{mL}$. Reducing power at $10 \mathrm{mg} / \mathrm{mL}$ extract concentration ranged from 0.11 to $0.84 \mathrm{~nm}$. Furthermore the extracts of these medicinal herbs in $80 \%$ methanol, $80 \%$ ethanol, $80 \%$ acetone, and $100 \%$ water were screened for antimicrobial activity by disc diffusion method against selected bacterial strains, Staphylococcus aureus, Escherichia coli, Bacillus subtilis, and Pasteurella multocida, and fungal strains, Aspergillus niger, Aspergillus flavus, Rhizopus solani, and Alternaria alternata. The extracts show better antimicrobial activity against bacterial strains as compared to fungal strains. Results of various assays were analyzed statistically by applying appropriate statistical methods.
\end{abstract}

\section{Introduction}

In developing countries, $65 \%-80 \%$ of population depends upon herbal medicines for primary health care [1]. Different categories of bioactive compounds are being isolated and characterized since the middle of 19th century. Most of these compounds are used as raw material for new medicines or as an active ingredient of existing medicines. Herbal medicines provide rich amount of tannins, alkaloids, flavonoids, phenolic compounds, and so forth, so these can be used in the treatment of several degenerative disorders $[2,3]$.

Antioxidants play a vital role in free radical scavenging and chain breaking of oxidation reactions both in vivo and in vitro. Free radicals possess free unpaired electrons, making them highly unstable and can extract electron from other molecules to attain stability causing them damage. Among the potential uses of antioxidants, some are prevention of diseases related to oxidative stress in humans and also prevention of oxidative reactions in pharmaceuticals, cosmetic products, and food [4].

Utilization of synthetic antioxidants, that is, citric acid, propyl gallate, butylated hydroxyanisole (BHA), and butylated hydroxytoluene (BHT) in foods, leads to many side effects. For instance, these synthetic antioxidants have carcinogenic effect in living systems and many reports indicated that they may enhance microsomal enzyme activity and also enlarge liver size. Consequently, there is an increase interest in finding natural antioxidant agents capable of scavenging free radicals and hindering oxidative rancidity of lipids, in this way, protecting living organisms from diseases and retarding food spoilage [5].

Vegetables, grains, and fruits contain a huge variety of bioactive phytochemicals. The antioxidants which are derived from plants may function as free radicals scavengers, metal 
ion chelators, and reducing agents. It has been demonstrated that plasma antioxidant activity increases after consuming food high in antioxidants. That is why phytochemicals may fight against oxidative stress by maintaining a balance between antioxidants and oxidants. Many medicinal plants possess antioxidant properties. Antioxidants extracted from plants either in form of raw extracts or as their chemical constituents are very effective to stop the destructive processes caused by oxidative stress $[6,7]$.

Our aim was to evaluate the antioxidant, antibacterial, and antifungal activities, total flavonoid contents, and total phenolic contents of 6 commonly medicinal plants, onion (Allium cepa), garlic (Allium sativum), mint (Mentha spicata), thyme (Thymus vulgaris), oak (Quercus), aloe vera (Aloe barbadensis Miller), and ginger (Zingiber officinale). Antioxidant activity was determined by measuring inhibition of peroxidation using linoleic acid system, measuring reducing power and DPPH scavenging activity. Antimicrobial activity was determined by disc diffusion assay against four selected bacterial strains, Pasteurella multocida, Staphylococcus aureus, Bacillus subtilis, and Escherichia coli, and four fungal strains, Alternaria alternata, Aspergillus niger, Rhizopus solani, and Aspergillus flavus.

\section{Materials and Methods}

Samples of different medicinal plants were collected from local market of Lahore and Sialkot, Pakistan. All chemicals used throughout the study were of analytical grade. All readings were taken in triplicate and average results are presented.

2.1. Preparation of Plants Extracts. Dried samples were grounded to pass 80 mesh sieves. Each sample $(20 \mathrm{~g})$ was extracted with $200 \mathrm{~mL}$ of $80 \%$ ethanol, $80 \%$ methanol, $80 \%$ acetone, and $100 \%$ distilled water and was shaken for 1 day at room temperature followed by filtrating. Solvent was evaporated after concentrating the extracts at $65^{\circ} \mathrm{C}$ under reduced pressure, using rotary evaporator. Each dry extract was then weighed; yield was calculated and stored in at $4^{\circ} \mathrm{C}$.

2.2. Determination of Total Phenolic Contents (TPC). To determine the amount of total phenolic contents in plant extracts, Folin-Ciocalteu reagent was used [8]. Briefly, $0.5 \mathrm{~mL}$ of Folin-Ciocalteu reagent and $7.5 \mathrm{~mL}$ distilled water was added in $50 \mathrm{mg}$ of crude plant extract and incubated for 10 minutes at room temperature. Afterwards, $20 \% \mathrm{Na}_{2} \mathrm{CO}_{3}$ $(1.5 \mathrm{~mL})$ was added in the resulting mixture and heated at $40^{\circ} \mathrm{C}$ for 20 minutes. Absorbance was taken at $755 \mathrm{~nm}$. The results were expressed as gallic acid equivalents $\mathrm{mg} / 100 \mathrm{~g}$ of crude plant matter.

2.3. Determination of Total Flavonoid Contents (TFC). To determine the amount of total flavonoid contents, procedure was used given at [8]. Briefly, $5 \mathrm{~mL}$ of distilled water and $0.1 \mathrm{~g} / \mathrm{mL}$ of aqueous plant extracts were mixed together. After 5 minutes, $0.3 \mathrm{~mL}$ of $5 \%$ sodium nitrite and $0.6 \mathrm{~mL}$ of $10 \%$ aluminium chloride were added. $2 \mathrm{~mL}$ of $1 \mathrm{M}$ sodium hydroxide was then added after another 5 minutes. At $510 \mathrm{~nm}$, absorbance was recorded.

TFC were expressed as catechin equivalents per dry matter.

2.4. Evaluation of Antioxidant Activity of Extracts. Antioxidant activities of plants extracts were measured using following antioxidant assays.

2.4.1. DPPH Scavenging Assay. DPPH scavenging assay was performed by method described by [9]. $0.2-500 \mu \mathrm{g} / \mathrm{mL}$ of each extract was dissolved in $95 \%$ methanol and in $90 \mu \mathrm{M}$ DPPH solution and left for 60 minutes. Then OD was measured at $515 \mathrm{~nm}$ wavelength. Butylated hydroxyl toluene was employed as a standard. DPPH radical scavenging activity was calculated by following equation:

$$
I \%=100-\frac{\left(\text { Absorbance }_{\text {blank }}-\text { Absorbance }_{\text {sample }}\right)}{\text { Absorbance }_{\text {blank }}} .
$$

2.4.2. Percent Inhibition in Linoleic Acid System. \% inhibition of linoleic acid peroxidation was used to determine the antioxidant activities of plants extracts as described by [10]. $0.13 \mathrm{~mL}$ of linoleic acid solution, $0.2 \mathrm{M}$ sodium phosphate buffer ( $\mathrm{pH}$ 6.6), and 99.8\% ethanol were mixed in $5 \mathrm{mg}$ of each plant extract and incubated for 72 hours at $40^{\circ} \mathrm{C}$. Colorimetric method was used to determine the extent of oxidation [11]. Briefly, ammonium thiocyanate solution $(30 \% \mathrm{w} / \mathrm{v})$, ethanol $(75 \% \mathrm{v} / \mathrm{v})$, ferrous chloride solution $(20 \mathrm{mM}$ in $3.5 \mathrm{HCl}$; v/v), and plant extracts were mixed under stirring. Absorbance was taken at $500 \mathrm{~nm}$. Butylated hydroxytoluene was employed as positive control. Percent inhibition of linoleic acid oxidation was calculated using

$\%$ inhibition of linoleic acid oxidation

$=100$

$$
-\left[\left(\frac{\text { Abs. increase of sample at } 175 \mathrm{~h}}{\text { Abs. increase of control at } 175 \mathrm{~h}}\right) \times 100\right] \text {. }
$$

2.4.3. Reducing Power Assay. Antioxidant activities of plants extracts by reducing power assay was done using protocols described by [10], with some modifications. $5-10 \mathrm{mg}$ of each dry concentrated extract was dissolved in $1 \%$ potassium ferricyanide and 0.2 M sodium phosphate buffer ( $\mathrm{pH} 6.6$ ). The resulting mixture was incubated for 20 minutes at $50^{\circ} \mathrm{C}$. Afterwards, $10 \%$ trichloroacetic acid was added followed by centrifugation at $5^{\circ} \mathrm{C}$. Upper layer was diluted with equal volume of deionized water and $0.1 \%$ ferric chloride. OD was measured at $700 \mathrm{~nm}$.

2.5. Antimicrobial Activity. The antimicrobial activities of medicinal plants extracts were determined using disc diffusion method. $100 \mu \mathrm{L}$ of suspension, having $10^{4} \mathrm{CFU} / \mathrm{mL}$ of fungal spores and $10^{8} \mathrm{CFU} / \mathrm{mL}$ of bacterial strains, was dispensed on potato dextrose agar and nutrient agar medium, respectively. 
Filter discs were individually impregnated with $30 \mu \mathrm{L}$ $(3 \mathrm{mg} / \mathrm{disc})$ of extract $(100 \mathrm{mg} / \mathrm{mL}, 90 \mu \mathrm{g} / \mathrm{disk})$ and placed on the previously inoculated agar with chosen microorganism. As positive control/standard, Rifampicin was used for bacterial strains. For fungal strains, Terbinafine was used. Petri plates were incubated at $4^{\circ} \mathrm{C}$ for 60 minutes. Then the petri plates were kept for 48 hours at $30^{\circ} \mathrm{C}$ for fungal spores and at $37^{\circ} \mathrm{C}$ for 1 day for bacteria. Antimicrobial activities were determined by determining growth inhibition zones diameter in millimeters (including $6 \mathrm{~mm}$ disc diameter) against the selected organisms and comparing results with the controls.

2.6. Statistical Analysis. The data is presented as mean value $\pm \mathrm{SD}$ value. One-way ANOVA procedure was used to perform the analysis of variance. Minitab software was used to calculate the significant differences $(p<0.05)$ between mean values.

\section{Results and Discussion}

Recently there is an increasing interest among the food researchers to distinguish antimicrobial compounds and antioxidants that have natural origin and are safe to use. Numerous flavors and herbs are accounted for to be a suitable source of antimicrobial and antioxidant agents. Over recent years, a number of studies have demonstrated that polyphenols that are present in dietary and herbal products hinder oxidative stress.

Preventive part of these foods is because of their components, particularly anthocyanidins, polyphenolics, flavonoids, and anthocyanins. Present research study was directed to assess the antioxidants, total phenolic contents, total flavonoid contents, and antimicrobial activities of extracts of garlic, onion, ginger, mint, aloe vera, thyme, and oak. Plant materials were extracted by using one extraction method, that is, orbital shaking, and four solvents, that is, $80 \%$ ethanol, $80 \%$ acetone, $80 \%$ methanol, and $100 \%$ water.

$\%$ yield $(\mathrm{mg} / 100 \mathrm{~g})$ of all plants extracts was within the range of 2.9 to $12.5 \mathrm{mg} / 100 \mathrm{~g}$. Maximum yield $(12.5 \mathrm{mg})$ was observed with $80 \%$ ethanolic extract of garlic. With regard to solvent efficacy, $80 \%$ ethanol was discovered more effective for the recovery of antioxidants from herbal plants.

Total phenolic contents of medicinal plants extracts obtained from four different solvent systems vary from $98.37 \mathrm{mg} \mathrm{GAE} / 100 \mathrm{~g}$ to $4.96 \mathrm{mg} \mathrm{GAE} / 100 \mathrm{~g}$ (Figure 1). However total phenolic content of $80 \%$ ethanolic ginger extract was observed to be maximum ( $98.37 \mathrm{mg} \mathrm{GAE} / 100 \mathrm{~g}$ ) and that of aqueous extract of oak was the lowest (4.96 mg GAE/100 g).

The total flavonoid contents of plant extracts obtained from four solvent systems ranged from 0.41 to $17.64 \mathrm{mg}$ $\mathrm{CE} / 100 \mathrm{~g}$ (Figure 2). The value of total flavonoids was observed to be highest, that is, $17.64 \mathrm{mg} \mathrm{CE} / 100 \mathrm{~g}$ obtained from $80 \%$ ethanolic garlic extract, while the minimum value was $0.41 \mathrm{mg} \mathrm{CE} / 100 \mathrm{~g}$ for aqueous oak extracts.

Antioxidant activity as determined by DPPH assay was found to be maximum in $80 \%$ ethanolic ginger extract $(82.2 \%)$ and minimum by aqueous extract of mint (20.9\%) (Figure 3 ). $\mathrm{IC}_{50}$ values, which represented the concentration

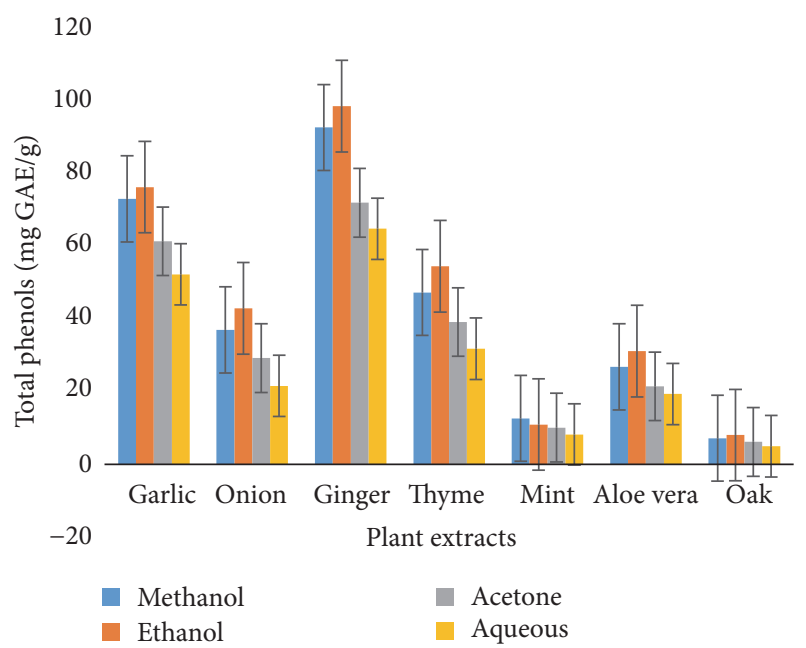

Figure 1: Total phenolic contents.

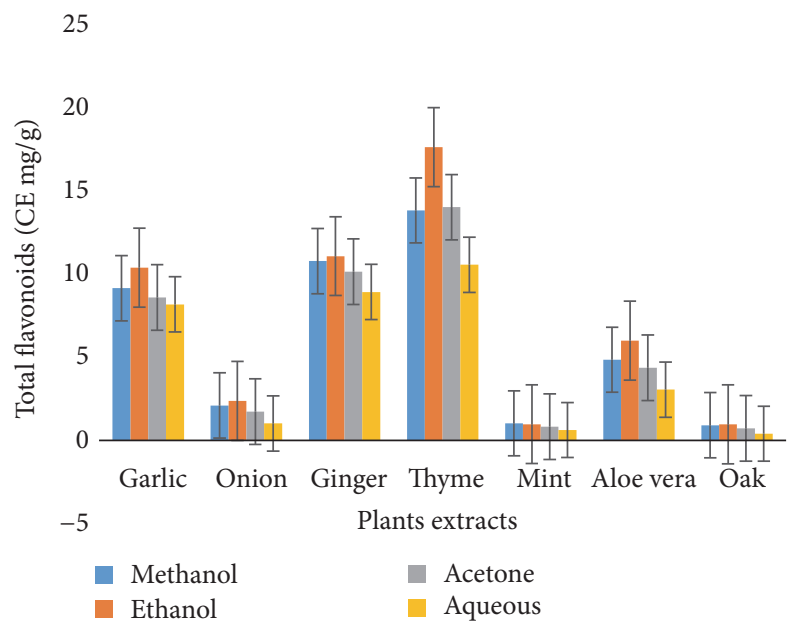

Figure 2: Total flavonoid Contents.

TABLE 1: DPPH radical scavenging activity $\left(\mathrm{IC}_{50}\right)$ of extracts from different medicinal plants.

\begin{tabular}{lcccc}
\hline Plants & Methanol & Ethanol & Acetone & Aqueous \\
\hline Garlic & 30.3 & 29.5 & 34.1 & 41.2 \\
Onion & 59.8 & 58.4 & 63.9 & 67.6 \\
Ginger & 24.6 & 17.8 & 28.3 & 32.5 \\
Thyme & 46.4 & 48.1 & 53.7 & 59.3 \\
Mint & 74.8 & 69.3 & 78.5 & 79.1 \\
Aloe vera & 52.3 & 51.1 & 57.7 & 60.5 \\
Oak & 65.7 & 63.3 & 69.6 & 71.2 \\
\hline
\end{tabular}

Values (mean $\pm \mathrm{SD}$ ) of extracts, analyzed individually in triplicate.

of antioxidants that caused 50\% neutralization of DPPH radicals, were calculated from the plot of inhibition percentage against concentration.

$\mathrm{DPPH}$ radical scavenging activity $\left(\mathrm{IC}_{50}\right.$ values) ranged from $17.8 \%$ to $79.1 \mu \mathrm{g} / \mathrm{mL}$ (Table 1 ).

The ethanolic extract of garlic was found to demonstrate maximum inhibition of peroxidation, reflecting highest antioxidant activity, while least inhibition was seen by 
TABLE 2: Reducing power (in terms of absorbance values at $700 \mathrm{~nm}$ ) of extracts from different medicinal plants.

\begin{tabular}{|c|c|c|c|c|c|}
\hline \multirow{2}{*}{ Plants } & \multirow{2}{*}{ Conc. $(\mathrm{mg} / \mathrm{mL})$} & Methanol & Ethanol & Acetone & Aqueous \\
\hline & & \multicolumn{4}{|c|}{ Absorbance at $700 \mathrm{~nm}$} \\
\hline \multirow{4}{*}{ Garlic } & 2.5 & $0.19 \pm 0.02$ & $0.21 \pm 0.05$ & $0.12 \pm 0.02$ & $0.09 \pm 0.02$ \\
\hline & 5 & $0.39 \pm 0.04$ & $0.44 \pm 0.03$ & $0.26 \pm 0.04$ & $0.16 \pm 0.04$ \\
\hline & 7.5 & $0.61 \pm 0.03$ & $0.67 \pm 0.04$ & $0.38 \pm 0.04$ & $0.26 \pm 0.02$ \\
\hline & 10 & $0.82 \pm 0.05$ & $0.84 \pm 0.06$ & $0.51 \pm 0.06$ & $0.34 \pm 0.05$ \\
\hline \multirow{4}{*}{ Onion } & 2.5 & $0.14 \pm 0.02$ & $0.16 \pm 0.02$ & $0.10 \pm 0.03$ & $0.06 \pm 0.03$ \\
\hline & 5 & $0.29 \pm 0.04$ & $0.33 \pm 0.03$ & $0.19 \pm 0.02$ & $0.10 \pm 0.05$ \\
\hline & 7.5 & $0.45 \pm 0.04$ & $0.50 \pm 0.02$ & $0.31 \pm 0.04$ & $0.17 \pm 0.03$ \\
\hline & 10 & $0.61 \pm 0.05$ & $0.63 \pm 0.05$ & $0.42 \pm 0.03$ & $0.25 \pm 0.06$ \\
\hline \multirow{4}{*}{ Ginger } & 2.5 & $0.21 \pm 0.03$ & $0.23 \pm 0.04$ & $0.17 \pm 0.02$ & $0.12 \pm 0.02$ \\
\hline & 5 & $0.40 \pm 0.04$ & $0.45 \pm 0.03$ & $0.33 \pm 0.04$ & $0.25 \pm 0.04$ \\
\hline & 7.5 & $0.62 \pm .08$ & $0.69 \pm 0.02$ & $0.50 \pm 0.04$ & $0.37 \pm 0.03$ \\
\hline & 10 & $0.84 \pm 0.04$ & $0.88 \pm 0.05$ & $0.64 \pm 0.06$ & $0.49 \pm 0.05$ \\
\hline \multirow{4}{*}{ Thyme } & 2.5 & $0.18 \pm 0.03$ & $0.2 \pm 0.02$ & $0.13 \pm 0.03$ & $0.09 \pm 0.03$ \\
\hline & 5 & $0.32 \pm 0.04$ & $0.41 \pm 0.03$ & $0.27 \pm 0.02$ & $0.19 \pm 0.02$ \\
\hline & 7.5 & $0.51 \pm 0.02$ & $0.59 \pm 0.04$ & $0.41 \pm 0.04$ & $0.28 \pm 0.04$ \\
\hline & 10 & $0.68 \pm 0.03$ & $0.76 \pm 0.02$ & $0.56 \pm 0.05$ & $0.37 \pm 0.09$ \\
\hline \multirow{4}{*}{ Mint } & 2.5 & $0.08 \pm 0.02$ & $0.1 \pm 0.02$ & $0.06 \pm 0.03$ & $0.03 \pm 0.03$ \\
\hline & 5 & $0.17 \pm 0.04$ & $0.19 \pm 0.03$ & $0.13 \pm 0.02$ & $0.07 \pm 0.05$ \\
\hline & 7.5 & $0.26 \pm 0.04$ & $0.31 \pm 0.02$ & $0.2 \pm 0.04$ & $0.11 \pm 0.03$ \\
\hline & 10 & $0.34 \pm 0.05$ & $0.38 \pm 0.05$ & $0.25 \pm 0.03$ & $0.14 \pm 0.06$ \\
\hline \multirow{4}{*}{ Aloe vera } & 2.5 & $0.15 \pm 0.03$ & $0.17 \pm 0.04$ & $0.12 \pm 0.02$ & $0.08 \pm 0.02$ \\
\hline & 5 & $0.29 \pm 0.04$ & $0.35 \pm 0.03$ & $0.25 \pm 0.04$ & $0.19 \pm 0.04$ \\
\hline & 7.5 & $0.42 \pm 0.07$ & $0.5 \pm 0.02$ & $0.37 \pm 0.04$ & $0.28 \pm 0.03$ \\
\hline & 10 & $0.58 \pm 0.02$ & $0.66 \pm 0.02$ & $0.51 \pm 0.03$ & $0.36 \pm 0.02$ \\
\hline \multirow{4}{*}{ Oak } & 2.5 & $0.05 \pm 0.02$ & $0.07 \pm 0.02$ & $0.02 \pm 0.03$ & $0.02 \pm 0.03$ \\
\hline & 5 & $0.11 \pm 0.04$ & $0.15 \pm 0.03$ & $0.05 \pm 0.02$ & $0.04 \pm 0.05$ \\
\hline & 7.5 & $0.16 \pm 0.04$ & $0.22 \pm 0.02$ & $0.09 \pm 0.04$ & $0.08 \pm 0.03$ \\
\hline & 10 & $0.21 \pm 0.05$ & $0.27 \pm 0.05$ & $0.13 \pm 0.03$ & $0.11 \pm 0.06$ \\
\hline
\end{tabular}

Values are the mean \pm standard deviation of triplicate.

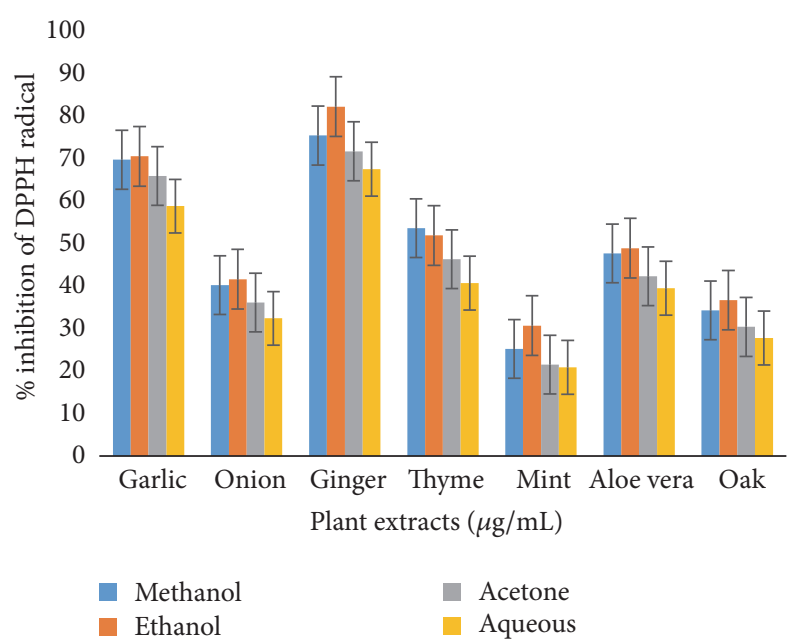

FIGURE 3: DPPH radical scavenging activity $\left(\mathrm{IC}_{50}\right)$ of extracts from different medicinal plants.

oaks. With regard to solvents, $80 \%$ ethanol was discovered more proficient for the recovery of antioxidant compounds from medicinal herbs as compared to other solvent systems (Figure 4).

With the increase of antioxidant compounds in tested medicinal plants, there was an observed increase in reducing power. Each plant extract displayed a dose-dependent reducing power (shown as absorbance at $700 \mathrm{~nm}$ ) within range of $2.5-10 \mathrm{mg}$ of extracts per $\mathrm{mL}$. Reducing power of ethanolic plant extracts was found to be highest while that of aqueous was found to be the lowest as shown in Table 2. Extraction efficiency of components with antioxidative properties was lowering in the following order: ginger $>$ garlic $>$ onion $>$ thyme $>$ aloe vera $>$ mint $>$ oaks.

The antimicrobial activity of all plants extracts was evaluated against four pathogenic bacterial strains (Bacillus subtilis, Staphylococcus aureus, Pasteurella multocida, and Escherichia coli) and four fungal strains (Aspergillus flavus, Rhizopus solani, Aspergillus niger, and Alternaria alternate). Antimicrobial potential of herbal plants extracts was assessed in terms of zone of inhibition of microbe's growth as shown in Table 3. All extracts showed better antibacterial activity as compared to antifungal activity. Results revealed that ethanolic and methanolic plant extracts were more active 


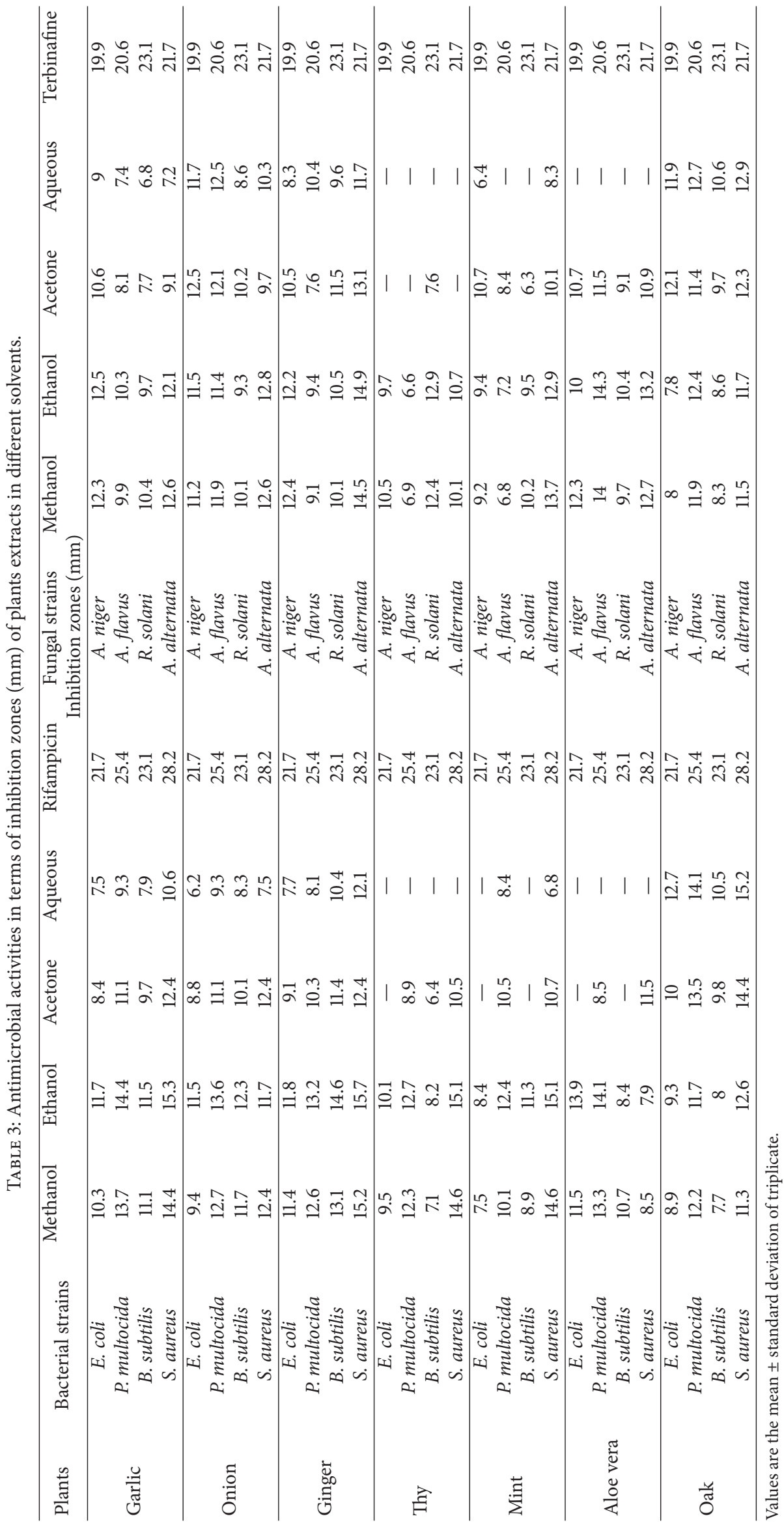




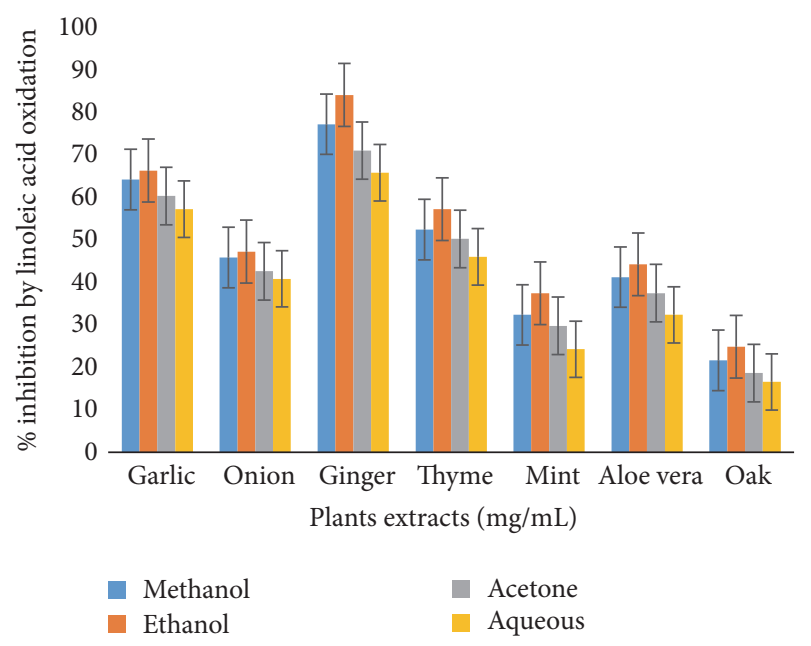

Figure 4: Percentage inhibition of linoleic acid oxidation.

against microbes as in comparison with acetone and aqueous extracts. Of all the plants extracts, ginger and garlic show better antibacterial and antifungal activity than others.

\section{Conclusion}

Results of our study show that tested plants, onion (Allium cepa), garlic (Allium sativum), mint (Mentha spicata), thyme (Thymus vulgaris), oak (Quercus), aloe vera (Aloe barbadensis Miller), and ginger (Zingiber officinale), are potent source of antioxidants. These plants extracts also showed good antibacterial and antifungal activities against pathogenic microbes which suggest that these plants could be used to treat various infections caused by microbes.

\section{Competing Interests}

The authors declare no competing interests regarding publication of this paper.

\section{Acknowledgments}

The authors are grateful to Director Institute of Chemistry, University of Punjab, Lahore, Pakistan, and Director of Department of Chemistry, Minhaj University, Lahore, Pakistan, to provide facilities for this research.

\section{References}

[1] J. O. Oladele and G. A. Ayoola, "Antioxidant activity among selected medicinal plants combinations (multi-component herbal preparation)," International Journal of Research in Health Science, vol. 3, no. 2, pp. 526-532, 2015.

[2] U. Ghias and A. Rauf, "Phytochemical screening and biological activity of the aerial parts of Elaeagnus umbellate," Scientific Research and Essays, vol. 7, no. 43, pp. 3690-3694, 2012.

[3] K. Ali, F. T. Artun, G. Özcan, G. Melikoğlu, S. Anıl, and N. Sütlüpınar, "In vitro evaluation of antioxidant activity of some plant methanol extracts," Biotechnology and Biotechnological Equipment, vol. 6, no. 6, pp. 1184-1189, 2015.
[4] A. Moure, J. M. Cruz, D. Franco et al., "Natural antioxidants from residual sources," Food Chemistry, vol. 72, no. 2, pp. 145171, 2001.

[5] C. A. Rice-Evans and L. Packer, Flavonoids in Health and Disease, CRC Press, Boca Raton, Fla, USA, 2nd edition, 2003.

[6] Z. Gokhan, A. Aktumsek, G. O. Guler, Y. S. Cakmak, and E. Yildiztugay, "Antioxidant properties of methanolic extract and fatty acid composition of Centaurea urvillei DC. subsp. hayekiana Wagenitz," Records of Natural Products, vol. 5, no. 2, pp. 123-132, 2011.

[7] N. Saeed, M. R. Khan, and M. Shabbir, "Antioxidant activity, total phenolic and total flavonoid contents of whole plant extracts Torilis leptophylla L," BMC Complementary and Alternative Medicine, vol. 12, no. 1, article 221, 2012.

[8] B. Sultana, F. Anwar, and R. Przybylski, "Antioxidant activity of phenolic components present in barks of Azadirachta indica, Terminalia arjuna, Acacia nilotica, and Eugenia jambolana Lam. Trees," Food Chemistry, vol. 104, no. 3, pp. 1106-1114, 2007.

[9] B. Bozin, N. Mimica-Dukic, N. Simin, and G. Anackov, "Characterization of the volatile composition of essential oils of some lamiaceae spices and the antimicrobial and antioxidant activities of the entire oils," Journal of Agricultural and Food Chemistry, vol. 54, no. 5, pp. 1822-1828, 2006.

[10] I. Shahid, M. I. Bhanger, and F. Anwar, "Antioxidant properties and components of some commercially available varieties of rice bran in Pakistan," Food Chemistry, vol. 93, no. 2, pp. 265272, 2005.

[11] Y. G. Chin, P. D. Duh, and D. Y. Chuang, "Antioxidant activity of anthraquinones and anthrone," Food Chemistry, vol. 70, no. 4, pp. 437-441, 2000. 

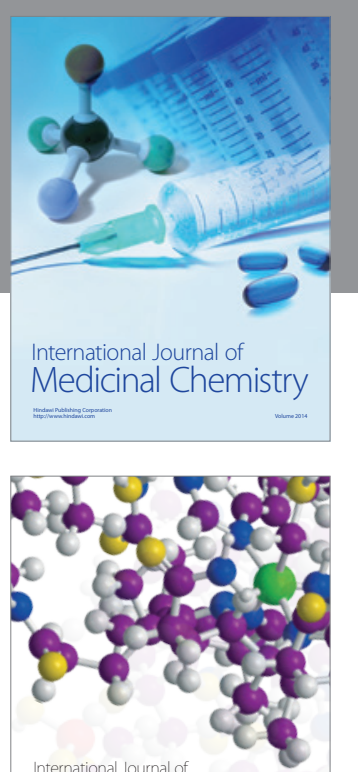

Carbohydrate Chemistry

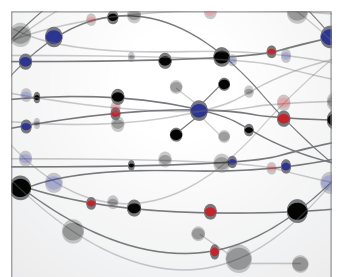

The Scientific World Journal
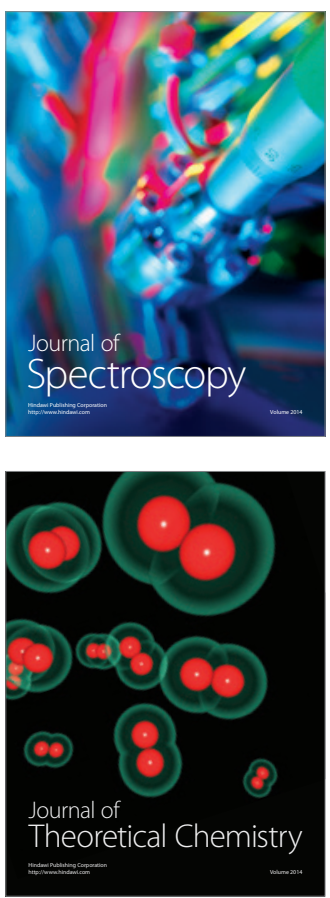
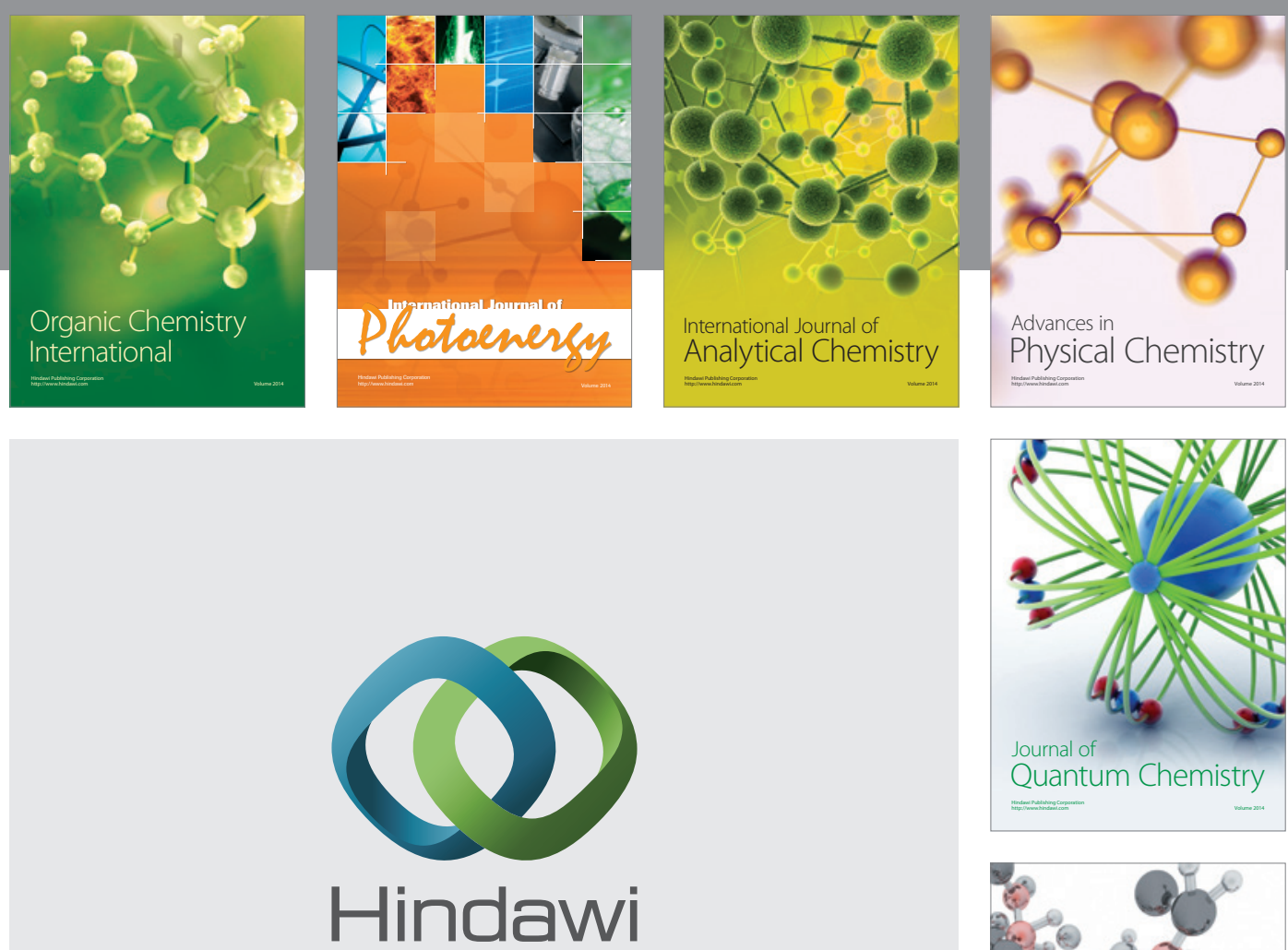

Submit your manuscripts at

https://www.hindawi.com

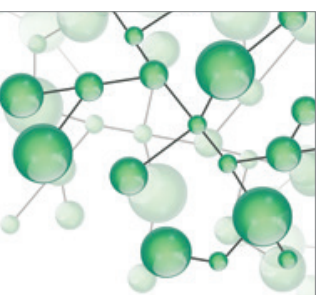

International Journal of

Inorganic Chemistry
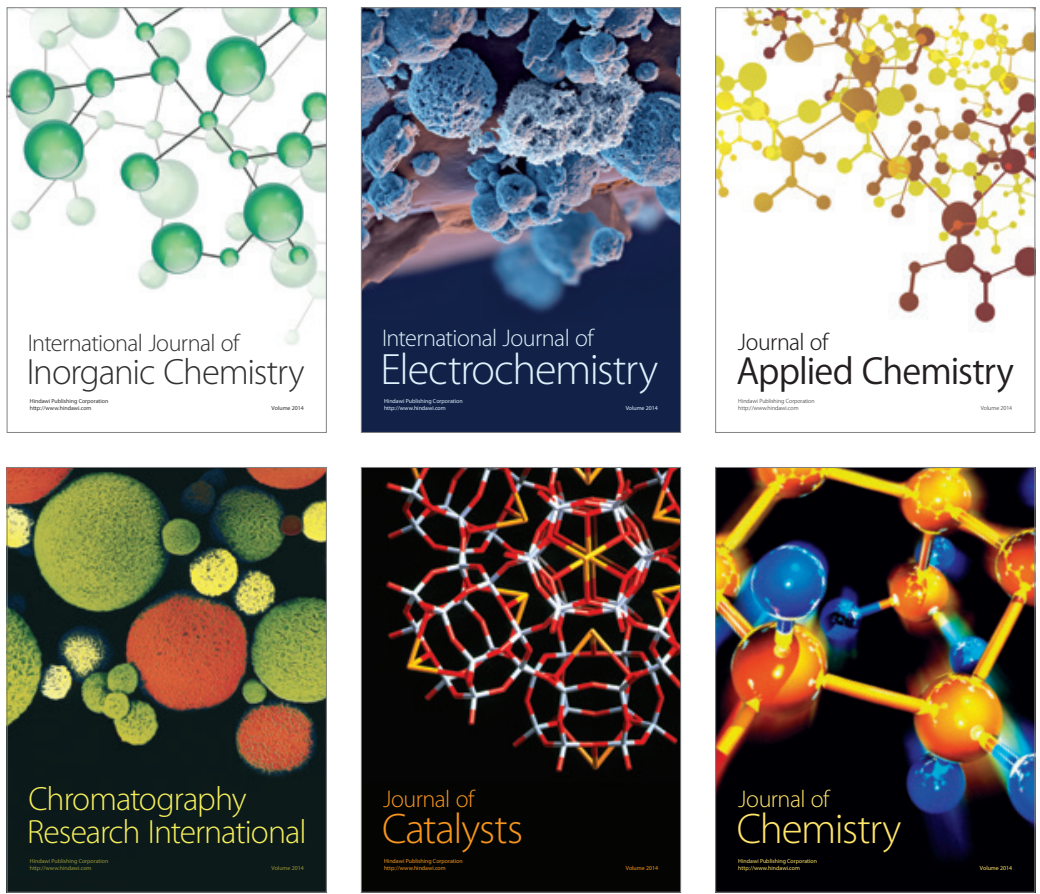

Journal of

Applied Chemistry
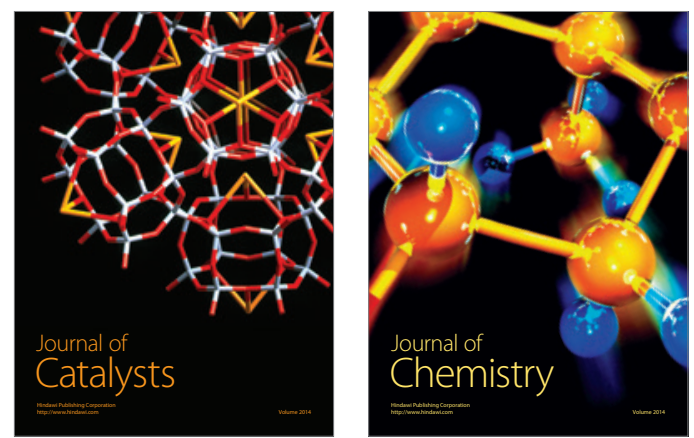
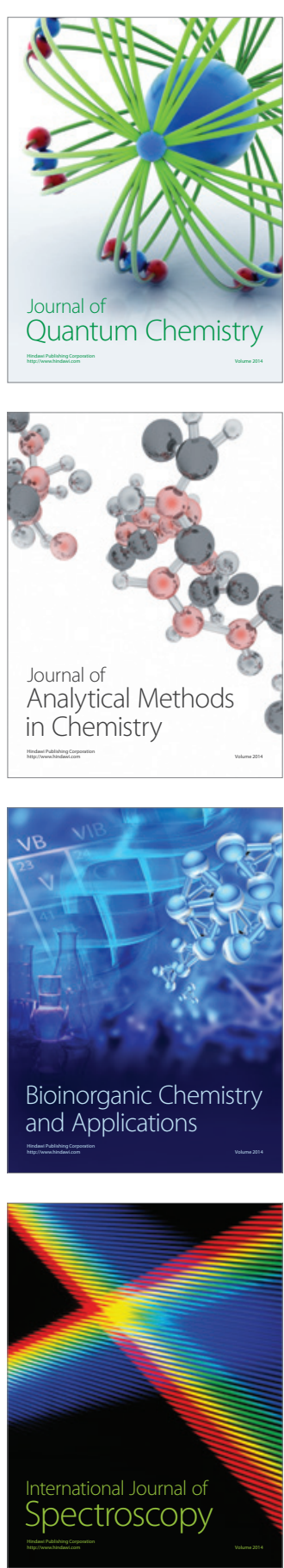